\title{
Un tiempo y un lugar para marcar diferencias
}

\author{
Sebastián R. Martínez ${ }^{1}$, Lola Murillo² \\ 1. Presidente del comité organizador del VI Congreso Nacional de Farmacéuticos Comunitarios. \\ 2. Presidenta del comité científico del VI Congreso Nacional de Farmacéuticos Comunitarios.
}

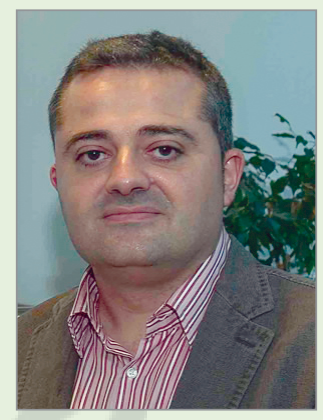

Sebastián R. Martínez

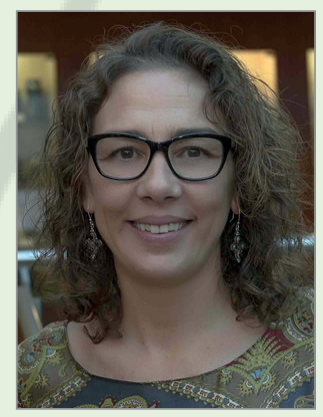

Lola Murillo
SEFAC celebra este año en mayo el VI Congreso Nacional de Farmacéuticos Comunitarios (www.congresosefac2014.org) con el reto de continuar creciendo y demostrar con hechos la importancia que tiene la labor del farmacéutico para mejorar el funcionamiento del sistema sanitario. El lugar escogido para la cita es Málaga, donde todos los que defendemos el valor asistencial de la farmacia comunitaria tenemos una cita imprescindible, pues se esperan más de mil asistentes procedentes de toda España e incluso de otros países.

Como cada dos años, los farmacéuticos comunitarios dispondremos del 22 al 24 de mayo de un espacio propio en el que exponer, debatir y compartir los resultados de nuestra actividad asistencial, cientifica y profesional. El lema de esta nueva edición es Marcando diferencias y con él queremos resaltar el protagonismo de nuestro colectivo para garantizar el uso adecuado de los tratamientos farmacológicos y colaborar activamente en la prevención y la promoción de la salud. Todo ello mediante un mejor aprovechamiento de nuestras capacidades y de la provisión de servicios profesionales farmacéuticos que contribuyen decisivamente a mejorar la salud de las personas.

Como presidentes de los comités organizador y científico, pretendemos que esta nueva edición del congreso de SEFAC sirva para marcar diferencias en muchos aspectos. El primero de ellos, ya apuntado antes, es el de demostrar que el sistema sanitario que todos conocemos y que atraviesa por momentos delicados no puede desaprovechar el caudal de conocimientos que atesoramos los farmacéuticos comunitarios. Y mucho menos en un momento de transformación como el que vivimos, en el que disminuyen los recursos disponibles y aumenta el envejecimiento poblacional, las enfermedades crónicas y la polimedicación. Como consecuencia de todo esto, aparecen nuevos retos como la conciliación de la medicación, la adherencia terapéutica y la atención domiciliaria, entre otros, que no pueden ni deben ser abordados sin contar con nuestro colectivo, pues no se debe olvidar que en mucha ocasiones somos tanto la puerta de entrada de los pacientes al sistema como el último profesional sanitario con el que tratan antes de enfrentarse en solitario a la toma de sus medicamentos.

En definitiva, el farmacéutico comunitario puede, con su trabajo, marcar las diferencias entre un Sistema Nacional de Salud realmente eficiente y otro en el que aumenten los problemas de salud y de costes derivados del uso inadecuado de los medicamentos. Y nosotros debemos ser capaces de hacer ver esto y alzar la voz si otros no son capaces de hacerlo.

Es por esto que para el sexto congreso de SEFAC se ha elaborado un extenso programa (de más de treinta sesiones) con el que se quiere transmitir toda nuestro potencial y en el que no faltarán asuntos como la colaboración multidisciplinar para mejorar la atención de las personas con enfermedades crónicas, al tiempo que conoceremos la opinión que los pacientes y la población general tienen de nuestra labor asistencial a través de un simposio específico. Es ésta la mejor manera de conocer si estamos cumpliendo con las expectativas y demandas de quienes más nos importan en nuestro día a día.

Pero además, queremos marcar diferencias mostrando la capacidad del farmacéutico comunitario para innovar y generar evidencia científica, mediante la presentación de los resultados de numerosos proyectos de investigación en ámbitos tan variados como la diabetes, la cesación tabáquica, el seguimiento farmacoterapéutico, la indicación farmacéutica... y también en nuevos servicios profesionales 
relacionados con la HTA, el riesgo vascular y la revisión del uso de la medicación. Sin olvidar tampoco otros puntos que se incluyen en el programa como la vinculación del farmacéutico con las nuevas tecnologías a través de la receta electrónica, la dispensación online de medicamentos sin receta, la informática aplicada a la farmacogenómica y el uso de aplicaciones móviles en la práctica asistencial farmacéutica.

A todo esto hay que añadir un listado amplio y variado de talleres de formación (anticoagulación, alergias, vacunas, sobrepeso y obesidad, desnutrición en ancianos y un largo etcétera) para facilitar a todos los inscritos la actualización y ampliación de conocimientos; un aspecto éste $\sin$ duda imprescindible en todo profesional sanitario.

Y repetiremos la instalación de una carpa con servicios farmacéuticos para la población. Una iniciativa que se llevará a cabo en el centro de Málaga y que a buen seguro será un éxito, como en la edición de Barcelona en 2012, pues ya cuenta con el apoyo de las instituciones sanitarias malagueñas.

Pero sin obviar, sino todo lo contrario, la alta calidad de los contenidos y ponentes que se darán cita en el VI Congreso Nacional de Farmacéuticos Comunitarios, lo más importante es la confirmación de que este evento es un cita ineludible para todos aquellos profesionales farmacéuticos que creen que la farmacia asistencial es el único camino posible para nuestra profesión. El congreso de SEFAC ha vivido una evolución acorde al crecimiento de la Sociedad y hoy podemos decir bien alto que no solo es un punto de encuentro en el que poner al día los conocimientos más vanguardistas de la farmacia comunitaria, sino que es un foro que marca tendencias y que estimula debates hasta entonces no planteados o, al menos, no consolidados como fueron en 2010 la propuesta de SEFAC sobre carrera profesional y en 2012 sobre nuevo modelo retributivo de la dispensación. Ahora, en 2014, y después de que en 2013 SEFAC haya sido una de las primeras entidades en presentar una propuesta firme de catálogo de servicios profesionales farmacéuticos, estamos convencidos de que volveremos a marcar diferencias en nuestro congreso, demostrando que somos una Sociedad innovadora con un congreso vanguardista que es capaz de adelantarse a los acontecimientos para señalar un camino que permita obtener y mantener con la colaboración de todos el reconocimiento científico y profesional que el farmacéutico comunitario se merece por parte del resto de agentes del sector salud.

Han pasado ya más de diez años desde el nacimiento de SEFAC. Un periodo en el que esta Sociedad ha demostrado tener claro su camino para tratar de mejorar la realidad de la farmacia comunitaria y marcar - una vez más-diferencias con todo aquello que quiere mantenerse inamovible. No ha sido ni es un camino de rosas. Los farmacéuticos comunitarios que hemos vivido su crecimiento y evolución podemos dar fe de lo mucho que ha costado disponer de una sociedad científica propia que nos represente en igualdad de condiciones que a otros profesionales de la salud. Ahora podemos decir que se ha conseguido y nos toca trabajar con ahínco por mantenerlo. Ha llegado ese tiempo. Y la mejor forma de hacerlo es citándonos en el acontecimiento más importante que aglutina a toda sociedad científica que se precie: $s u$ congreso nacional. Es ahí donde tenemos la mejor oportunidad posible de demostrar a todo el sistema sanitario lo que podemos hacer en beneficio de la salud y debemos aprovecharlo.

Tenemos el sitio, tenemos el programa, tenemos los ponentes. Málaga nos espera.

Juntos. Marcando diferencias. 